Copyright (C) 2016 by Academic Publishing House Researcher

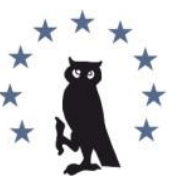

Published in the Russian Federation

European Researcher

Has been issued since 2010.

ISSN 2219-8229

E-ISSN 2224-0136

Vol. 104, Is. 3, pp. 148-155, 2016

DOI: 10.13187/er.2016.104.148

www.erjournal.ru

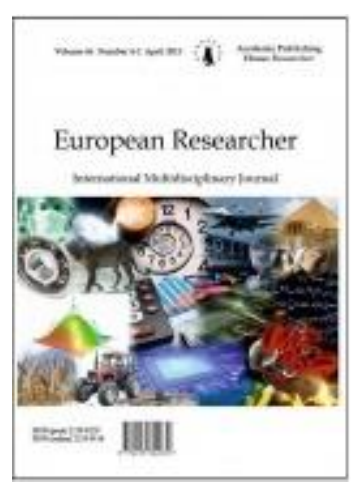

Economic sciences

Экономические науки

UDC 338

\title{
The Analysis of the Industrial Policy in Japan
}

${ }^{1}$ Natalia V. Kuznetsova

${ }^{2}$ Natalia A. Vorobeva

${ }^{1}$ Far Eastern Federal University, Russian Federation

Suhanova Str., 8, Vladivostok, Primorye region 690950

Doctor of Economic Science, Professor

E-mail: ipatovanat@mail.ru

${ }^{2}$ Far Eastern Federal University, Russian Federation

Suhanova Str., 8, Vladivostok, Primorye region 690950

$\mathrm{PhD}$ (Economics), Assistant Professor

\section{Abstract}

The paper analyzes the issues of the Japanese experience of industrial policy, which managed to overcome significant challenges in economic and social development of the country. Japanese experience of industrial policy is unique, due to the fact that the government provides the planned economic policy of integrated industrial development at the macro and micro levels, with emphasis on the competitive advantages of some regions of the country and on the active involvement of the private sector in various projects of public-private partnership. At the same time, the mechanism of Japanese industrial policy has demonstrated its viability in different historical periods of the economic development of the country.

Keywords: industrial policy, Japan, planning, government regulation.

\section{Введение}

Изучая вопросы пространственного размещения промышленности, можно отметить успешный опыт многих стран - как западных (США, Германия, Великобритания, Франция), так и восточных (Япония, Южная Корея) - который говорит о том, что можно проводить эффективную промышленную политику, направленную на ускорение развития промышленности и экономики в целом.

Как отмечает исследователь Р. Гринберг, «страны (Япония, Южная Корея, Китай, Малайзия, Тайвань), которым удалось совершить экономический прорыв и превратиться в экономически развитые, осуществили это исключительно при помощи успешной промышленной политики» [1].

Следует обратить особое внимание на японский опыт промышленной политики в плановой организации промышленности страны, так как именно эта страна, после Второй 
Мировой Войны, имела полностью разрушенную промышленную базу и с 1950-х гг. выстраивала государственную промышленную политику таким образом, чтобы с нуля возродить национальную промышленность, не имея при этом практически никаких природных ресурсов. Этот опыт построения промышленной политики является уникальным и заслуживает детального анализа.

В Японии государство активно вовлечено в процесс экономического развития страны. Государственное вмешательство отвечает насущным задачам японской экономики на всех этапах ее развития. Государство разрабатывает стратегии развития, определяет отраслевые приоритеты, широко применяет на практике меры стимулирования экспорта и защиты от зарубежных конкурентов.

Согласно общепринятой точки зрения, большинство успехов Японии в послевоенный период - это результат действия японского правительства, которое осуществляет комплекс мер экономической политики, называемые японская модель государственного регулирования. Хотя в последнее время появилось множество дискуссий по этому вопросу.

\section{1. Роль государства в реализации промышленной политики Японии}

Формы и методы государственного регулирования экономики Японии схожи с мерами, применяемыми другими развитыми странами. Вмешательство государства в экономику осуществляется в нескольких формах: 1) государственная собственность и предпринимательство; 2) перераспределение национального дохода через бюджет; 3) макроэкономическая политика; 4) административно-юридическое регулирование развития отдельных отраслей.

Однако в Японии преобладает практика использования неформальных методов государственного регулирования, к числу которых можно также отнести специфический инструмент регулирования - административное руководство («мадогучи сидо»), а также взаимодействие государства и частного бизнеса через сеть организаций (Кэйданрэн).

Экономическая система послевоенной Японии отличалась от других развитых стран сравнительной слабостью элементов свободного рынка. Это было обусловлено большой ролью в ней двух других системообразующих структур - государства и так называемого группирования в сфере бизнеса.

Стратегическим направлением политики роста в послевоенный период было стимулирование накопления капитала. Этот курс в значительной степени основывался на таких рычагах, как огромные государственные инвестиции в расширение и совершенствование экономической инфраструктуры, субсидии, дешевый кредит, различные налоговые и амортизационные льготы для стимулирования внутренних и внешних источников финансирования инвестиций частных предприятий, научно- технического прогресса и экспорта. В частности, в этом процессе большую роль сыграли налоговые стимулы для мелких сбережений населения.

Чалмерс Джонсон [2] впервые сформулировал принципы японской модели регулирования экономики, его называют основоположником теории государственного регулирования экономики Японии. Он утверждал, что в Японии правительство практически «выращивало» промышленность, в то время как в западных странах правительства просто устанавливали правила игры. Он высказывает мнение, что быстрый рост японской экономики и производительности труда в 1960-х и начале 1970-х нельзя объяснить только влиянием экономических, институциональных или культурных факторов. Правительственная промышленная политика оказала существенное влияние на уровень инвестиций в стратегически важные отрасли экономики.

Главная задача экономической политики Японии остается неизменной уже многие годы: частный бизнес и государство совместно работают над повышением международной конкурентоспособности страны.

Ответственность за выбор направления развития экономики лежала на чиновниках центральных министерств. Главную роль здесь играло Министерство международной торговли и промышленности (MITI, Ministry of International Trade and Industry), созданное в 1949 г., сейчас переименовано в METI (Ministry of Economy, Trade and Industry) Министерство экономики, торговли и промышленности. 
М. Портер подчеркивал важную роль сложной системы взаимосвязей японских правительственных и бизнес институтов, которые определяли характер конкуренции и кооперации в японской экономике. Эта система включает в себя кроме METI, Министерство финансов, Министерство почты и телекоммуникаций, Банк Японии, Агентство экономического планирования, отраслевые ассоциации промышленников, Кейрэцу, Кэйданрен, крупные корпорации, национальные профсоюзы [3, с. 42-43].

METI и Министерство международной торговли и индустрии помогало вырабатывать предприятиям оптимальную стратегию развития, облегчало ведение переговоров с иностранными партнерами, что в свою очередь, способствовало проникновению японских компаний на зарубежные рынки.

В целом развитие промышленности в Японии происходило при активном взаимодействии трех основных сил: государства (представленного ведущими министерствами), представителями крупного капитала и профсоюзами (выражавшими интересы трудовых коллективов).

Промышленная политика занимает особое место среди различных направлений экономической политики Японии, так как именно здесь государственная политика отличается наибольшей комплексностью, целенаправленностью и последовательностью.

Промышленная политика представляет собой комплекс экономических, политических и организационных мероприятий на разных уровнях национальной экономической системы, направленной на поддержание и рост национальной промышленности. Она носит двойственный характер: стимулирование экономического роста и отраслевая модернизация экономики, с одной стороны, и определение долгосрочной экономической стратегии развития экономики, с другой стороны.

Промышленная политика в Японии создала благоприятные условия для развития ряда отраслей, ставших основой промышленного роста страны, способствовала созданию благоприятного инвестиционного климата в Японии.

Как отмечает зарубежный экономист Д.Окимото [4, с.32-34], японские исследователи признают за рынком две функции большой важности: «он предопределяет структуру частных инициатив» и «обеспечивает превосходный механизм обратной связи, который создает возможности для саморегулирования системы», однако, имеет и ряд своих недостатков. Поэтому японцы убеждены, что для получения желаемых результатов «невидимая» рука рынка должна работать вместе с «видимой» рукой правительства [4]. Этот подход к рынку наиболее ярко проявляется в промышленной политике.

В общем виде, японская научная литература определяет промышленную политику как совокупность мер государственного воздействия, направленного на формирование отраслевой структуры промышленности с целью повышения эффективности использования факторов производства.

Начиная с послевоенного периода государство в Японии приступило к «структурированию» экономического роста, т.е. к проведению промышленной политики, которая отличалась комплексностью, последовательностью и целенаправленностью.

Целесообразно рассмотреть основных действующих лиц промышленной политики Японии. Доминирующую роль играет японское государство, наряду с ним в проведении промышленной политики значительное место занимают и другие организации.

Промышленные ассоциации являются важным звеном в разработке межотраслевых интересов, а также средством коммуникации между отраслями и правительством. Наряду с промышленными ассоциациями система организации разработки промышленной политики включает бизнес-федерации. В Японии наиболее влиятельными являются следующие организации: Кэйданрэн, Кэйдзай Доюкай, Никкэйрэн и Ниссё.

Для координирования экономической политики была создана специальная экономическая организация «Кэйданрэн», федерация более 110 ведущих промышленных ассоциаций. В составе этой организации действуют комитеты, которые проводят исследования по вопросам развития бизнеса. Идеологией «Кэйданрэн» является свободное предпринимательство, однако в своих действиях она исходит из интересов не только частного сектора, но и государства.

Кэйданрэн представляет собой отраслевые и территориальные ассоциации финансовых и промышленных кругов, а также банки и корпорации, она способствовала: развитию японской экономики путем содействия либерализации торговли, поощрению международной конкуренции, проведению административной и налоговой реформы. Никкэйрэн занималась вопросами трудовых отношений, во многом способствовала созданию системы трудового менеджмента в Японии. 
За годы существования Кэйданрэн и Никкэйрэн наладили постоянное взаимодействие. В условиях затянувшегося кризиса японской экономики назрела необходимость в совместном решении насущных проблем. С 2001 г. в Японии начала проводиться реорганизация правительственной структуры. В 2002 г. появилась самая крупная общенациональная организация предпринимателей - Ниппон Кэйданрэн. Новая организация призвана сыграть важную роль в возрождении экономики страны, прежде всего, решить задачу оживления активности промышленных кругов, страдающих от дефляции [5].

Механизм проведения промышленной политики Японии менялся от прямого административного вмешательства до мер стимулирующего характера. Представим наглядно этот механизм в общем виде на рис. 1.

Стратегия экономического развития страны (пятилетние планы)

Стратегия развития отдельных отраслей (индикативное планирование)

Скорректированный вариант развития отрасли
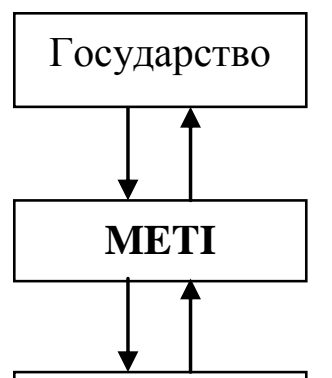

Бюро МЕTI

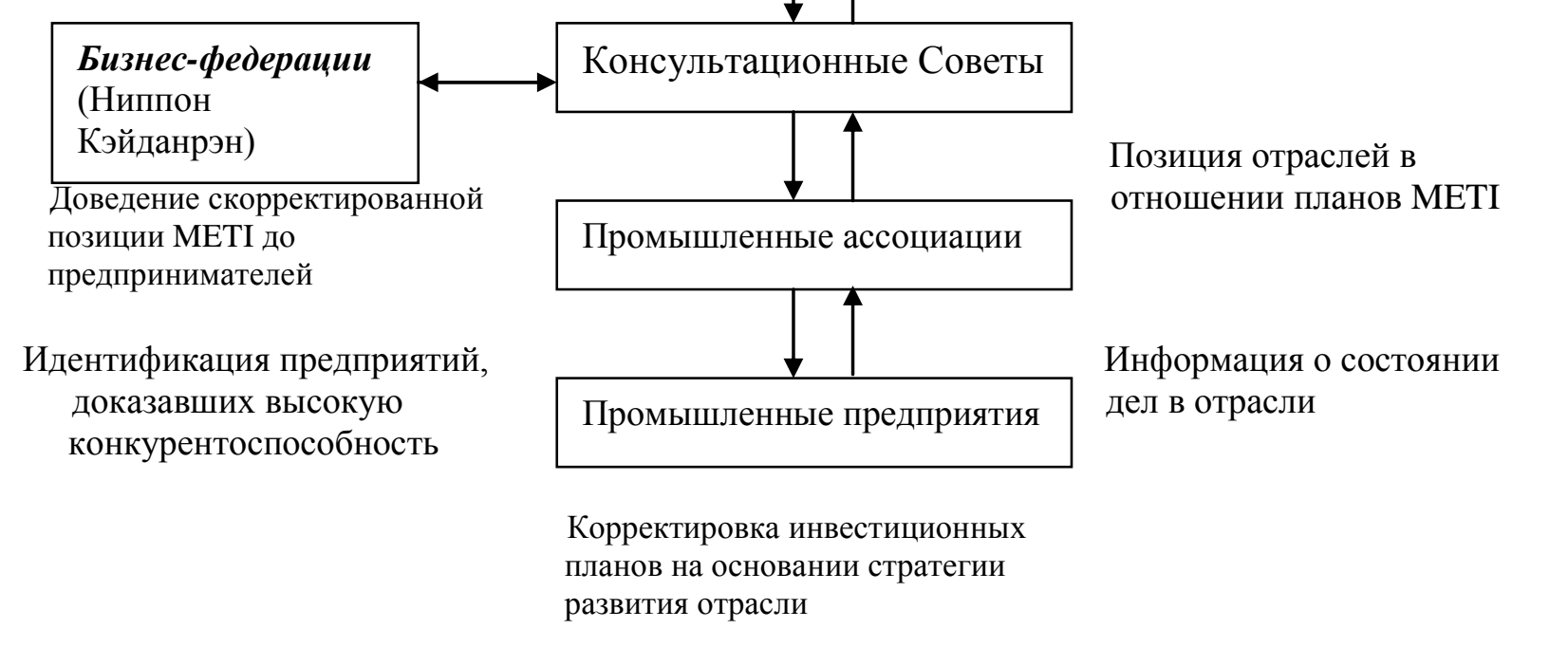

Перечень мероприятий по поддержке отраслей (запрос на финансирование)

Мероприятия по поддержке отраслей (определение объемов финансирования)

Доведение позиций предпринимателей до МЕTI

Составлено по: [6; 7; 8; 9; 10; 11]

\section{Puc. 1. Механизм реализации промышленной политики Японии}

Анализируя представленный механизм промышленной политики Японии можно отметить, что существует вертикальный поток информации, идущий как со стороны государства до предприятий, так и обратной связью. На уровне правительства определяются генеральные пятилетние планы, а на следующем уровне соответствующие ведомства METI выделяют приоритетные отрасли дальнейшего финансирования. Затем Бюро МЕTI осуществляет индикативное планирование развития отдельных отраслей, т.е. разрабатываются детализированные планы дальнейшего развития.

На уровне Консультационных советов и промышленных ассоциаций доводится до деловых кругов позиция METI в области конкретной отрасли производства. В свою очередь, на уровне предприятий идет разработка собственных планов на основе общегосударственных стратегий. Затем работает механизм обратной связи, в результате которого правительству докладываются необходимые объемы финансирования, необходимого для достижения планируемого уровня развития. 
На протяжении всей послевоенной экономики представленный механизм проведения промышленной политики активно действовал.

Первый этап - этап восстановления (1946-1948 гг.), хотя темпы роста промышленности в этот период были высокими, однако, они были обеспечены за счет повышения степени загрузки существующих производственных мощностей, а не за счет создания новых. В целом на данном этапе сохранялась довоенная структура производства, в которой преобладала доля отраслей легкой промышленности (текстильная). Здесь притворялась в жизнь концепция «кэйся сэйсан хосики», т.е. «система приоритетных производств», основная идея которой - дать толчок развитию определенных отраслей и постепенно вывести экономику из разрухи [12]. Для восстановления экономики было решено расширить производство угля (основной энергоноситель Японии). В результате угледобыча и черная металлургия стали приоритетами развития.

С созданием в 1949 г. при МITI Совета по рационализации производства начался второй этап промышленной политики (1950-е гг.). Целью политики провозглашалось повышение эффективности и технического уровня японских промышленных предприятий путем концентрации усилий на: повышении качества используемого сырья, обновлении производственных мощностей, модернизации всей системы управления предприятием. Было выделено около 50 приоритетных производств.

На данном этапе изменился сам механизм реализации промышленной политики - от прямого вмешательства в деятельность частного сектора государство перешло к использованию мер стимулирующего характера.

Главным направлением развития японской промышленности 70-80-х гг. стало урегулирование положения дел в структурно больных отраслях (отрасли с высокой энерго- и материалоемкостью: черная и цветная металлургия, нефтехимия, целлюлозно-бумажная промышленность, отрасли легкой промышленности, судостроение).

В 9о-е гг. METI продолжало регулировать развитие промышленности, хотя его масштабы, объекты и цели существенно изменились. В силу вступили несколько законов, целью которых стала поддержка усилий предприятий по перестройке производства. Предприятие, желавшее получить поддержку государства, должно представить в Министерство «План обновления производства». Если он получает одобрение, предприятие может рассчитывать на льготы: низкопроцентные кредиты Банка развития, введение льготной $25 \%$-ной нормы амортизации для нового оборудования, льготное налогообложение доходов, льготы по налогу на недвижимость и др.

Японские специалисты отмечают, что принятие данного закона свидетельствует о достижении консенсуса между бизнесом и государством в отношении необходимости продолжения промышленной политики, которая существует как одно из направлений государственного регулирования. Если раньше она представляла собой мощный механизм, определявший стратегию и ход промышленного развития страны, то теперь это точечное воздействие на этот процесс.

Подводя итоги анализа формирования и реализации промышленной политики в Японии в целом, можно с уверенностью сказать, что она создала благоприятные условия для развития базовых отраслей и способствовала формированию благоприятного инвестиционного климата.

В частности, наибольший положительный эффект был достигнут в следующих областях: в автомобильной промышленности был выстроен полноценный механизм реализации промышленной политики (займы Японского Банка развития, схема ускоренной амортизации, субсидии на НИОКР); в электронной отрасли (проект VLSI в области производства полупроводников) [12].

\section{2. Современный этап развития промышленной политики Японии}

С конца 2008 г. правительство Японии начало принимать антикризисные меры, которые характеризуются четкой структурированностью. Проводимая антикризисная программа имеет три основные цели:

1. снятие общественного беспокойства (акцент на поддержание стабильного уровня жизни и занятости населения, повышение уровня медицинского и социального обеспечения и поддержку образования);

2. создание «общества устойчивости» (через энергосбережение, сильное сельское, лесное и рыбное хозяйство - доведение самообеспеченности продовольствием до 50 \%);

3. содействие адаптации к новой структуре издержек и усиление потенциала роста через поддержку малых и средних предприятий. 
Для достижения поставленных целей были приняты дополнительные бюджеты. В совокупности выделенные бюджетные средства на антикризисную программу составляют 750 млрд. долл., в том числе 120 млрд. долл. на прямые выплаты и налоговые льготы (2 \% ВВП страны).

Что касается направления поддержки, то японское правительство определило три приоритетных направления: повседневная жизнь людей, малый и средний бизнес, региональная политика.

Заложенные в бюджете 2009 г. антикризисные меры по поддержанию повседневной жизни людей включают: страхование по безработице; поддержка внутреннего спроса напрямую через людей (введение ежегодных субсидий на взрослого - 12 тыс. иен, на ребенка - 20 тыс. иен); создание фонда поощрения введения новых рабочих мест в регионах; снижение налоговых ставок для физ. лиц. Помощь малому и среднему бизнесу включает гарантии по чрезвычайным займам и специальные кредиты (снижение налога на прибыль малых и средних предприятий до $18 \%)$.

Третьим направлением поддержки с помощью дополнительных бюджетных средств государство определило региональную политику. Новые составляющие включают: децентрализацию власти, расширение полномочий местных и региональных властей; компенсацию сокращения налоговых поступлений; увеличение доли остающихся в регионе национальных налогов.

В условиях глобального кризиса в Японии была разработана «Стратегия нового экономического роста», в которой кроме уже обозначенных антикризисных мер, основными направлениями на долгосрочную перспективу являются: высокие экологические стандарты (энергосберегающие технологии, снижение парникового эффекта, активное использование нетрадиционных видов энергии); высокие стандарты здравоохранения и высокая продолжительность жизни; разработка новой стратегии развития информационнокоммуникационных технологий; мобилизация внутренних ресурсов страны (создание известных брендов, развитие туризма и др.).

Одним из основополагающих принципов антикризисной политики Японии является принцип государственности. В кризисных условиях весьма важно возвращение государства в экономику региона. Однако формы и механизм его присутствия должны быть новыми, а характер государственного регулирования кардинально изменен. Дерегулирование нуждается в замене на регулирование с учетом кризисной ситуации. Государственные инвестиции в регионе должны стать не столько главным источником, а катализатором частных инвестиций.

В частности, в развитии экономики России принцип государственности должен реализовываться через национальные проекты, государственно-частное партнерство, государственные компании и введение элементов госмонополии в экспортно-ориентированных сырьевых отраслях экономики.

России следует особо обратить внимание на японский опыт расширения внутреннего спроса за счет поддержки доходов населения через введение субсидий населению - весьма эффективная мера в условиях кризиса. Такая практика существенно смягчает последствия финансового кризиса на уровне семей, помогает укрепить доверие населения к власти. В регионе это поможет снизить социальную напряженность. Кроме ориентации на поддержку населения в социальной сфере, следует обратить внимание на создание инфраструктуры регионов.

\section{Заключение}

Государственное планирование экономики в Японии носит наглядный пример системного подхода к планированию. В экономике этой страны государство играет огромную роль, демонстрируя эффективность своего вмешательства для координации и состыковки интересов регионов, частного бизнеса и населения страны, проводя планомерную промышленную политику. При этом государство своевременно реагирует на изменения в мировой экономике и детально прорабатывает четкий план действий, согласно новым условиям экономического развития.

Обобщим выводы, сделанные нами в рамках оценки промышленной политики Японии:

- государство в Японии является важнейшей составляющей экономической системы (ведущая роль Министерства экономики, торговли и промышленности);

- государственное планирование экономики в Японии носит наглядный пример системного подхода к планированию, являясь важнейшим элементом государственной национальной и региональной политик; 
- государственные экономические планы, содержащие программу государственных инвестиционных расходов с разбивкой по отраслям, оказывают значительное влияние на экономику Японии как на макроуровне, так и на микроуровне, стимулируя корпорации осуществлять стратегическое планирование своего развития;

- наряду с доминирующей ролью государства в проведении промышленной политики значительную роль играют промышленные ассоциации и бизнес-федерации, которые активно включены в механизм реализации промышленной политики страны, их действия четко скоординированы на всех уровнях;

- государство непосредственно участвует в региональном экономическом развитии через предпринимательскую и финансовую деятельность общественных корпораций;

- распространенной формой совместного участия государства и частного сектора в реализации проектов регионального развития - создание компаний «третьего сектора» в качестве оптимальной формы привлечения частного капитала к общественно полезной деятельности (развитию инфраструктуры);

- японская региональная экономическая политика опирается на прочную основу законодательно закрепленной системы финансово-экономических отношений между федеральным и местным управлением;

- особенностями территориальной структуры японской экономики являются: ярко выраженная диспропорциональность; исторически сложившаяся ориентировка промышленности Японии на экспорт определила сосредоточение ее на тихоокеанском побережье страны, сформировав Тихоокеанский промышленный пояс;

- основополагающий принцип современной антикризисной политики Японии - принцип государственности, который предполагает «возвращение» государства в экономику региона; при этом основным направлением поддержки с помощью дополнительных бюджетных средств была определена региональная политика.

\section{Благодарности}

Результаты были получены в рамках выполнения государственного задания Минобрнауки России в сфере научной деятельности по Заданию № 26.1478.2014/К «Структурные преобразования экономики России посредством интеграционного встраивания в отраслевые рынки ATP».

\section{Примечания:}

1. Гринберг Р. Российская структурная политика: между неизбежностью и неизвестностью / Р. Гринберг // Вопросы экономики, 2008. № 3. С. 46-57.

2. Chalmers Johnson, MITI and Japanese Miracle. The Growth of Industrial Policy, 1925-1975. Stanford University Press, Stanford, California, 1992.

3. Портер М., Такеути Х., Сакакибара М. Японская экономическая модель / М. Портер, Х. Такеути, М. Сакакибара. Может ли Япония конкурировать? М.: 2005. С.42-43.

4. Okuno-Fujiwara M., Suzumura K. Economic Analysis of industrial Policy: A Conceptual Framework Through the Japanese Experience / M. Okuno-Fujiwara, K. Suzumura. Tokyo, 1985. pp. 31-42.

5. Тимонина И.Л. Япония: региональная экономика и политика / И.Л. Тимонина. М.: Институт востоковедения РАН, 2002. 379с.

6. Бутуханов А.В. Механизм реализации промышленной политики в Японии: автореф. дис. канд. эконом. наук / А.В. Бутуханов. Хабаровск: Издательство ХГАЭП, 2005. 24 с.

7. Edgington D.W. The Geography of Endaka: Industrial Transformation and Regional Employment Changes in Japan / D.W. Edgington // Regional Studies, Vol.28.5, pp.521-535.

8. Sato Hitoshi. Effects of CEO's characteristics on internationalization of small and medium enterprises in Japan. 2011. [Electronic resource]. URL: http://www.rieti.go.jp/jp/publications/ dp/11e026.pdf

9. Дружинин Н.Л. Институциональные факторы развития послевоенной экономической системы Японии / Н.Л. Дружинин. СПб.: Изд-во С.-Петерб. Ун-та, 2007. 195 с.

10. Авдулов А., Кулькин А. Государственная научно-техническая политика Японии / А.Авдулов, А. Кулькин. М., 2000. С. 30.

11. Rodrik D. Industrial Policy for the Twenty-First Century / D. Rodrik. KSG Faculty Research Working Paper Series 2004, RWP04-047. Cambridge, MA, Harvard University, John F. Kennedy School of Government, 2004, p. 36-37.

12. Лебедева И.П. Япония: промышленность и предпринимательство (вторая половина XX начало XXI в.) / И.П. Лебедева. Ин-т востоковедения РАН. М.: Вост.лит., 2007. 223 с. 


\title{
References
}

1. Grinberg R. Rossiiskaya strukturnaya politika: mezhdu neizbezhnost'yu i neizvestnost'yu / R. Grinberg // Voprosy ekonomiki, 2008. № 3. S. 46-57.

2. Chalmers Johnson, MITI and Japanese Miracle. The Growth of Industrial Policy, 1925-1975. Stanford University Press, Stanford, California, 1992.

3. Porter M., Takeuti Kh., Sakakibara M. Yaponskaya ekonomicheskaya model' / M. Porter, Kh. Takeuti, M. Sakakibara. Mozhet li Yaponiya konkurirovat'? M.: 2005. S.42-43.

4. Okuno-Fujiwara M., Suzumura K. Economic Analysis of industrial Policy: A Conceptual Framework Through the Japanese Experience / M. Okuno-Fujiwara, K. Suzumura. Tokyo, 1985. pp. 31-42.

5. Timonina I.L. Yaponiya: regional'naya ekonomika i politika / I.L. Timonina. M.: Institut vostokovedeniya RAN, 2002. 379s.

6. Butukhanov A.V. Mekhanizm realizatsii promyshlennoi politiki v Yaponii: avtoref. dis. kand. ekonom. nauk / A.V. Butukhanov. Khabarovsk: Izdatel'stvo KhGAEP, 2005. 24 s.

7. Edgington D.W. The Geography of Endaka: Industrial Transformation and Regional Employment Changes in Japan / D.W. Edgington // Regional Studies, Vol.28.5, pp.521-535.

8. Sato Hitoshi. Effects of CEO's characteristics on internationalization of small and medium enterprises in Japan. 2011. [Electronic resource]. URL: http://www.rieti.go.jp/jp/publications/ dp/11e026.pdf

9. Druzhinin N.L. Institutsional'nye faktory razvitiya poslevoennoi ekonomicheskoi sistemy Yaponii / N.L. Druzhinin. SPb.: Izd-vo S.-Peterb. Un-ta, 2007. 195 s.

10. Avdulov A., Kul'kin A. Gosudarstvennaya nauchno-tekhnicheskaya politika Yaponii / A.Avdulov, A. Kul'kin. M., 2000. S. 30.

11. Rodrik D. Industrial Policy for the Twenty-First Century / D. Rodrik. KSG Faculty Research Working Paper Series 2004, RWP04-047. Cambridge, MA, Harvard University, John F. Kennedy School of Government, 2004, p. 36-37.

12. Lebedeva I.P. Yaponiya: promyshlennost' i predprinimatel'stvo (vtoraya polovina KhKh - nachalo XXI v.) / I.P. Lebedeva. In-t vostokovedeniya RAN. M.: Vost.lit., 2007. 223 s.

УДК 338

\section{Анализ японского опыта реализации промышленной политики}

${ }^{1}$ Наталия Викторовна Кузнецова

${ }^{2}$ Наталья Александровна Воробьева

\author{
1-2 Дальневосточный федеральный университет, Российская Федерация \\ 1 Доктор экономических наук, профессор \\ E-mail: ipatovanat@mail.ru \\ 2 Кандидат экономических наук, доцент
}

Аннотация. В работе проводится анализ практического опыта развития промышленной политики Японии, в рамках которого удалось преодолеть существенные проблемы в социально-экономическом развитии страны. Японский опыт проведения промышленной политики является уникальным, в связи с тем, что правительство страны поэтапно проводит плановую экономическую политику комплексного развития промышленности на макро и микро- уровнях, при этом делая акцент на конкурентных преимуществах отдельных регионов страны и на активное вовлечение частного бизнеса в различные проекты государственно-частного партнерства. При этом, механизм проведения промышленной политики Японии продемонстрировал свою жизнеспособность в различные исторические периоды развития экономики страны.

Ключевые слова: промышленная политика, Япония, планирование, государственное регулирование. 